\title{
Diphenoxylate Hydrochloride Therapy in the Diarrhoea of Malnourished Infants
}

\author{
JOHN BITAR, SAMIR S. NAJJAR, and RAJA Y. ASFOUR \\ From the Department of Pediatrics, American University of Beirut, Lebanon
}

\begin{abstract}
Bitar, J., Najjar, S. S., and Asfour, R. Y. (1970). Archives of Disease in Childhood, 45, 190. Diphenoxylate hydrochloride therapy in the diarrhoea of malnourished infants. In a double-blind study on 45 malnourished infants with moderately severe non-specific diarrhoea, diphenoxylate hydrochloride proved to be an effective antidiarrhoeal agent when the diarrhoea was acute, but not as effective when the diarrhoea was chronic.
\end{abstract}

In 1959, Janssen, Jageneau, and Huygens reported the antidiarrhoeic properties of diphenoxylate hydrochloride. Several clinical studies which followed (Barowsky and Schwartz, 1962; Collins, 1966; Kasich, 1961; Merlo and Brown, 1960; Van-Derstappen, Vantrappen, and Vandenbronche, 1960; Weingarten, Weiss, and Simon, 1961; Winkelstein, 1961) showed that it was an effective antidiarrhoeal agent; this, however, was challenged by Harris and Beveridge (1965) who, in a doubleblind study of 50 children with gastro-enteritis, found no beneficial effect. The earlier favourable reports on this drug prompted us to evaluate in a double-blind study its effect on the non-specific diarrhoea of malnourished infants.

\section{Subjects and Methods}

Our study included 45 malnourished infants with moderately severe diarrhoea, admitted to the Solarium Hospital of Beirut. The clinical findings on these infants are summarized in Table $I$. The diarrhoea in all of them was severe enough to require admittance to hospital. Those who had diarrhoea for less than 10 days were considered acute cases and those who had diarrhoea for $\mathbf{1 0}$ days or more were considered to have chronic diarrhoea. Vomiting was associated with the diarrhoea in some patients. Infants having pathogenic organisms in their stools were eliminated from the study. Haemoglobin, haematocrit, and urine analysis were done routinely. Initially the infants were started on glucose in water and a pectin preparation orally; those who were vomiting were given intravenous therapy until the vomiting ceased and then started on oral feeding. Milk was then introduced gradually reaching a full

Received 11 August 1969. strength formula only on the fourth or the fifth day in hospital.

The medications on trial consisted of diphenoxylate hydrochloride and a placebo. Both were in liquid form and had the same colour, and were supplied (by G. B. Searle \& Co.) as solutions labelled A and B, which were assigned to alternate patients in the chronological order in which they were admitted to the hospital. The coese of the label was not revealed to us until the completion of the study. The dose of the drug and the placeßo varied with the age of the patient (Table II). TRe treatment was continued until the diarrhoea subsided or for a total of one week. If there was no satisfactofy response during this period or the condition of the patient deteriorated, the study was discontinued and the patient was shifted to the general ward for further

TABLE I

Comparison of Infants on Diphenoxylate Hydischloride with Control Group

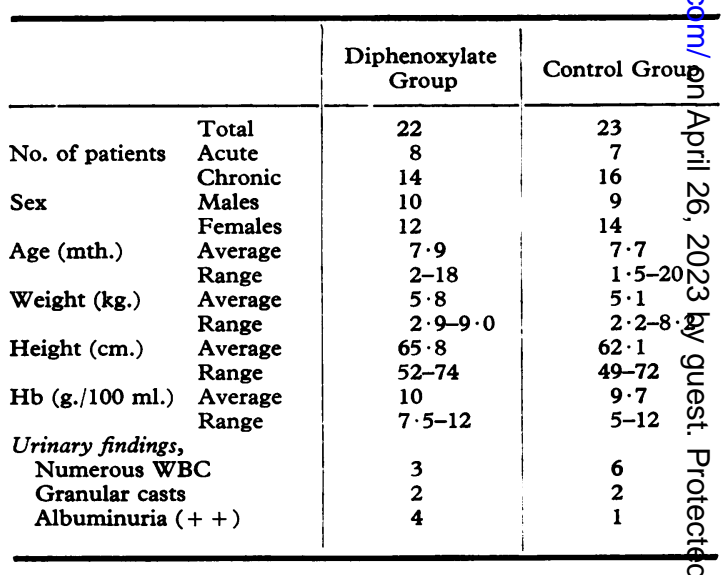


management. A patient was considered to have responded satisfactorily to treatment and was ready for discharge when the state of hydration, temperature, appetite, and gain in weight were satisfactory and when the infant had stools that were normal in number, colour, and consistency.

TABLE II

Dose of Diphenoxylate Hydrochloride or Placebo

\begin{tabular}{c|c|c}
\hline $\begin{array}{c}\text { Age } \\
\text { (mth.) }\end{array}$ & $\begin{array}{c}\text { Dose } \\
\text { per day }\end{array}$ & $\begin{array}{c}\text { Diphenoxylate } \\
\text { Content (mg.) }\end{array}$ \\
\hline $3-6$ & $2 \mathrm{ml} \times 3$ & 3 \\
$6-12$ & $2 \mathrm{ml} \times 4$ & 4 \\
$12-24$ & $2 \mathrm{ml} \times 5$ & 5 \\
\hline
\end{tabular}

\section{Results}

The time it took for each patient to respond satisfactorily to therapy is shown graphically in the Fig. This figure also includes those who failed to respond after 7 days of treatment.

Acute diarrhoea. Of the 15 infants with acute diarrhoea, 8 received diphenoxylate hydrochloride in addition to supportive treatment, and 7 did not. The number of infants who had responded by the end of each day of treatment is shown in Table III.

The durations of treatment in the two groups were ranked and a Mann-Whitney U-test performed, since we have two small and probably non-normal samples. A U-value of 9 is achieved, which is significant with $\mathrm{p}<0.025$ in a one-tailed test (since equality with placebo would be regarded as equivalent to inferiority).

As can be seen, the addition of diphenoxylate hydrochloride treatment substantially decreased the time taken to respond. Significantly more patients were ready for discharge earlier in this group.

The superior response of the patients in the treated group reached statistical significance accord-
TABLE III

\begin{tabular}{|c|c|c|c|}
\hline \multirow{3}{*}{ Day } & \multicolumn{2}{|c|}{ Acute Diarrhoea } & \multirow{3}{*}{$\begin{array}{c}\text { P-Value } \\
\text { (one-tailed test) }\end{array}$} \\
\hline & \multicolumn{2}{|c|}{$\begin{array}{l}\text { No. of Patients Ready for Discharge } \\
\text { on or Before Day Indicated }\end{array}$} & \\
\hline & $\begin{array}{c}\text { Diphenoxylate } \\
\text { Hydrochloride } \\
\text { (8 patients) }\end{array}$ & $\begin{array}{c}\text { Placebo } \\
\text { (7 patients) }\end{array}$ & \\
\hline $\begin{array}{l}1 \\
2 \\
3 \\
4 \\
5 \\
6 \\
7\end{array}$ & $\begin{array}{l}1 \\
4 \\
5 \\
6 \\
6 \\
6 \\
8\end{array}$ & $\begin{array}{l}0 \\
0 \\
0 \\
0 \\
1 \\
4 \\
5\end{array}$ & $\begin{array}{l}\text { NS } \\
0.05 \\
0.019 \\
0.0055 \\
0.032 \\
\text { NS } \\
\text { NS }\end{array}$ \\
\hline
\end{tabular}

ing to Fisher's exact test on the 2nd, 3rd, 4th, and 5 th days of treatment, the greatest difference being at the 4th day when 6 out of 8 patients on diphenoxylate had been discharged but none from the placebo group.

Chronic diarrhoea. Of the patients with chronic diarrhoea, 9 out of 14 patients receiving diphenoxylate hydrochloride responded within one week, 2 in the first three days, while 8 of the 16 receiving placebo responded in seven days, none in the first three days of therapy. However, a Mann-Whitney U-test was performed as before, yielding a U-value of 110 which is not significant ( $\mathrm{p}$-one tail-almost $0 \cdot 5$ ).

\section{Discussion}

Diphenoxylate hydrochloride in this doubleblind study proved to be an effective drug in the control of the acute form of non-specific diarrhoea in the malnourished infant; such infants responded better and in a shorter time than controls who received a placebo, and the difference was statistically significant. The chronic diarrhoea of these malnourished infants also seemed to respond better to diphenoxylate hydrochloride than to placebo,

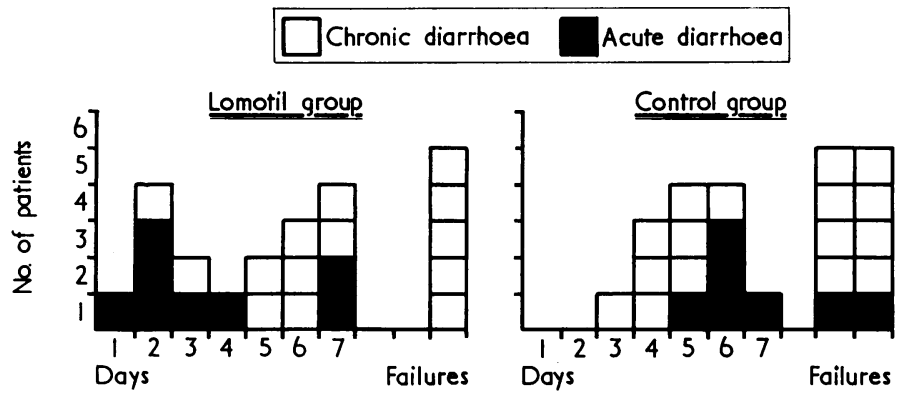

FIG.-Shows the day on which diarrhoea responded to therapy in the control and treatment group. 
but the difference was not statistically significant. The observation that acute diarrhoeas respond better to therapy is consistent with the experience of several authors (Anderson, 1966; Bowie, Brinkman, and Hansen, 1965). Once the diarrhoea continues beyond a certain period it becomes selfperpetuating, secondary disaccharide deficiency sets in, normal bowel flora invade the inflamed mucosal membranes of the gut, and a Shwartzmanlike reaction may occur (Fraser and Berry, 1967), bowel motility becomes abnormal, and the impairment of the digestive and pancreatic secretions (Anderson, 1966), as well as the deficiency of vitamins and iron, will make the diarrhoea resistant to modes of therapy that would have been effective at earlier stages.

We observed no side-effects that could be attributed to diphenoxylate hydrochloride. However, the main undesirable effects of this drug, which include nausea, drowsiness, dizziness, restlessness, and abdominal cramps (Merlo and Brown, 1960; Van-Derstappen et al., 1960), could have been missed in the young age-group studied. The relative safety of this drug, however, should not permit its indiscriminate use especially when dealing with infectious diarrhoeas. The mode of action of diphenoxylate hydrochloride is still not completely known. Its chemical resemblance to morphine derivatives suggests that it acts by increasing the intestinal tone and decreasing the propulsive movements of the bowel (Barowsky and Schwartz, 1962; Janssen et al., 1959). Radiclogical studies show a conspicuous reduction in the transit time of barium meal after diphenoxylate hydrochloride (Cayer and Sohmer, 1961; Demeulenaere, 1958). Such a reduction of intestinal motility may prove harmful in infectious diarrhoeas where quick expulsion of intestinal content may be a protective mechanism. Thus, normal guineapigs given $S$. typhimurium orally as well as opiate died earlier and with more extensive disease than guinea-pigs given the organisms without opiate (Kent, Formal, and Labrec, 1966). The enhanced pathogenicity of $S$. typhimurium was attributed to the decreased transit time induced by opium. Previous animal studies using shigellae showed similar findings (Dammin, 1967; Formal et al 1963). These studies should caution against the sole use of drugs that may interfere with protectiv $\overrightarrow{\vec{g}_{\mathrm{g}}}$ physiological mechanisms of the body without the use of effective and specific antimicrobials.

\section{REFERENCES}

Anderson, C. M. (1966). Intestinal malabsorption in childhoo d Archives of Disease in Childhood, 41, 571 .

Barowsky, H., and Schwartz, S. A. (1962). Method for evaluating diphenoxylate hydrochloride; comparison of its antidiarrhe@ effect with that of camphorated tincture of opium. fournal of the American Medical Association, 180, 1058.

Bowie, M. D., Brinkman, G. L., and Hansen, J. D. L. (1965 Acquired disaccharide intolerance in malnutrition. Fournal of Pediatrics, 66, 1083.

Cayer, D., and Sohmer, M. F. (1961). Long-term clinical studię̧ with a new constipating drug, diphenoxylate hydrochlorider North Carolina Medical fournal, 22, 600.

Collins, C. D. (1966). Lomotil in treatment of post-vagotom diarrhoea. British Medical fournal, 2, 560. Dammin, G. J. (1967). Acute diarrheal disease. Medical Time

Demeulenaere, L. (1958). Action du R 1132 sur le transit gastro intestinal. Acta Gastro-enterologica Belgica, 21, 674.

Formal, S. B., Abrams, G. D., Schneider, H., and Sprinz, H. (1963). Experimental Shigella infections. VI. Role of the small intestine in an experimental infection in guinea pigs
fournal of Bacteriology, 85, 119 .

Fraser, G. C., and Berry, C. (1967). Mortality in neonatal Hirschsprung's disease: with particular reference to enterocolitiso fournal of Pediatric Surgery, 2, 205.

Harris, M. J., and Beveridge, J. (1965). Diphenoxylate in the treatment of acute gastro-enteritis in children. Medic日) fournal of Australia, 2, 921 .

Janssen, P. A. J., Jageneau, A. H., and Huygens, J. (1959). Synthet antidiarrheal agents-1. Some pharmacological properties R 1132 and related compounds. Fournal of Medicinal and Pharmaceutical Chemistry, 1, 299.

Kasich, A. M. (1961). Treatment of diarrhea in irritable colo including preliminary observations with a new antidiarrhest agent, diphenoxylate hydrochloride (Lomotil). Americo
fournal of Gastroenterology, 35, 46.

Kent, T. H., Formal, S. B., and Labrec, E. H. (1966). Acuto enteritis due to Salmonella typhimurium in opium-treatef guinea pigs. Archives of Pathology, 81, 501 .

Merlo, M., and Brown, C. H. (1960). The effect of diphenoxylate

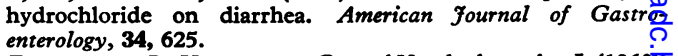

Van-Derstappen, G., Vantrappen, G., and Vandenbronche, J. (1960̄. Long term clinical studies with R-1132, a new constipatipg. drug. Gastroenterology, 39, 725.

Weingarten, B., Weiss, J., and Simon, M. (1961). A clinic@ evaluation of a new antidiarrheal agent. American fournal $\overrightarrow{9}$ Gastroenterology, 35, 628.

Winkelstein, A. (1961). Symptomatic treatment of diarrhea wi diphenoxylate. American fournal of Gastroenterology, 36, 698

Correspondence to Dr. S. S. Najjar, Department of Pediatrics, School of Medicine, American University Beirut, Beirut, Lebanon. 